Jurnal

Kardiologi Indonesia

J Kardiol Indones. 2013;34:142-4

ISSN 0126/3773

Forum Aritmia

\title{
Takikardia QRS lebar dengan hemodinamik tidak stabil
}

Yoga Yuniadi

Kasus

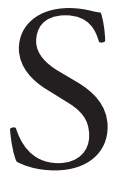

eorang laki-laki, 56 tahun datang ke UGD RS daerah di Jawa Tengah dengan keluhan lemas yang sudah dirasakan sejak seminggu sebelum masuk RS. Pasien juga mengeluh berdebar dan muntah-muntah. PPemeriksaan fisik didapatkan TD 90/60, RR 24 kpm dengan laju nadi sulit dihitung karena terlalu cepat. Tanda fisik lain tidak menonjol kecuali terdapat edema di kedua tungkai. Rekaman EKG diperlihatkan pada gambar 1.

Bagaimana bersikap terhadap keadaan klinis pasien

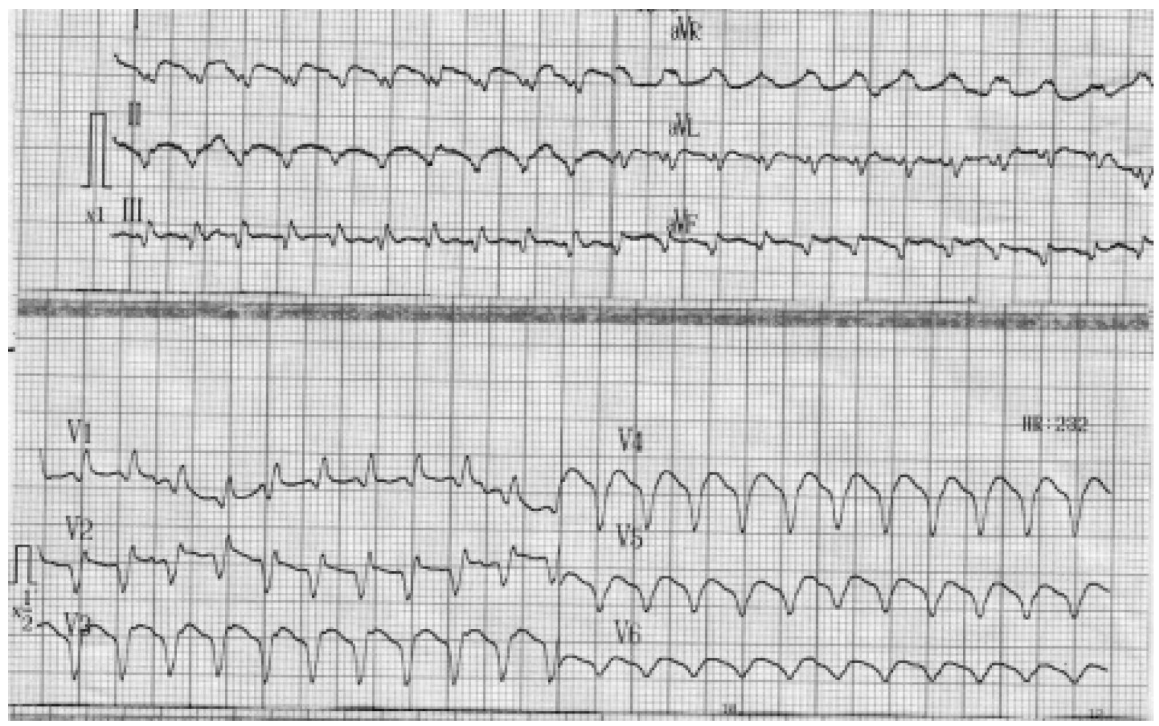

Gambar 1. Rekaman EKG 12 sadapan. Takikardia QRS lebar dengan gelombang P bebas (anak panah)

\section{Alamat korespondensi:}

Dr. dr. Yoga Yuniadi, SpJP, Divisi Aritmia, Departemen Kardiologi dan Kedokteran Vaskuler FKUI dan Pusat Jantung Nasional Harapan, Kita, JI S Parman Kav 87 Jakarta I I420, E-mail: yogayun@yahoo.com ini? Kata kuncinya adalah: Takikardia QRS lebar dengan hemodinamik tidak stabil. Pastikan bahwa instabilitas hemodinamik akibat takikardia lalu segera lakukan kardioversi tersinkronisasi 100 joule!!1 


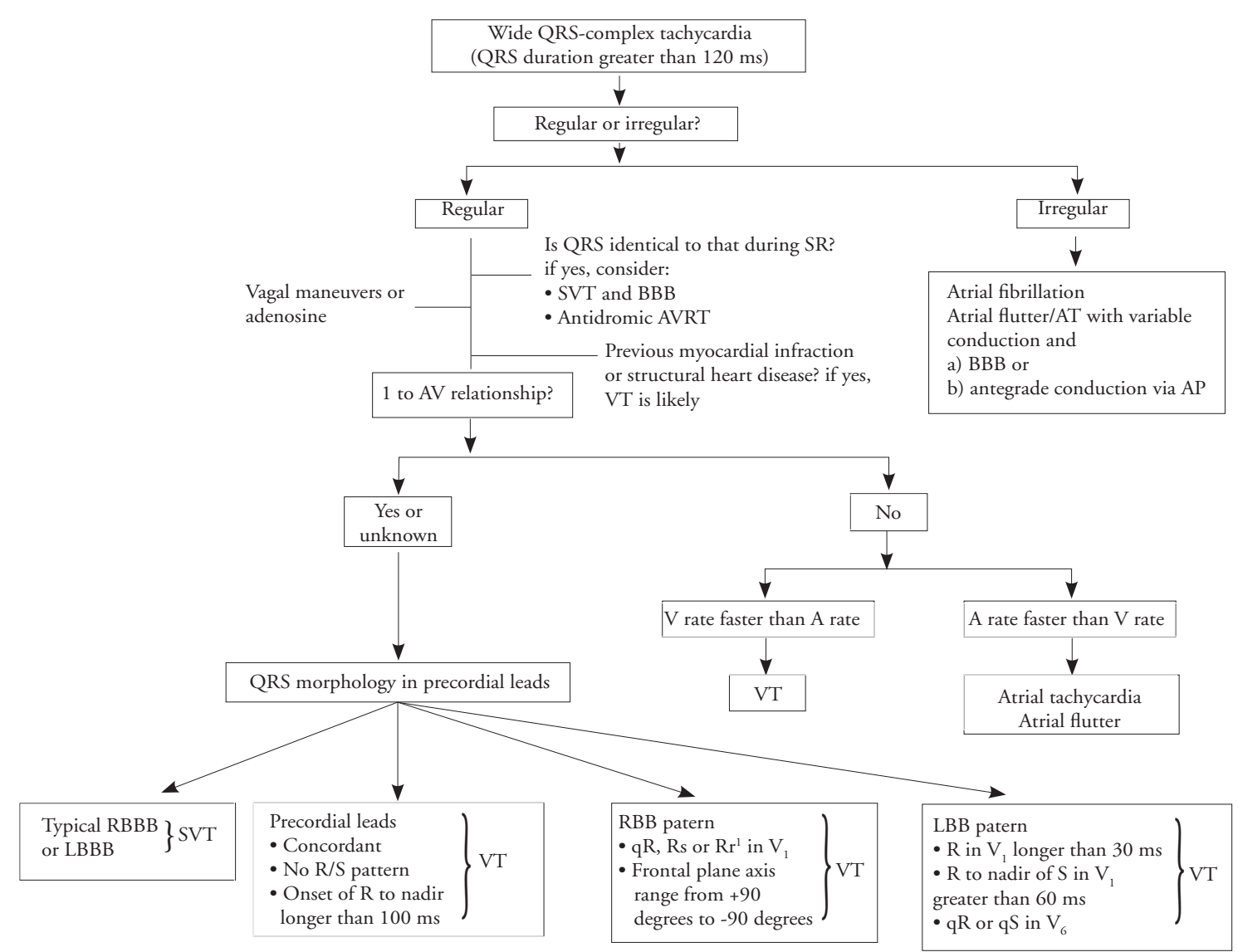

Gambar 2. Algoritme diagnosis takikardia QRS lebar rekomendasi American College Cardiology

Sebetulnya tidak terlalu sulit membuat diagnosis segera kelainan irama di atas. Akan tetapi situasi yang huru-hara akibat laju jantung yang sangat tinggi (230 kpm) dan hemodinamik yang tidak stabil dapat menyebabkan keterlambatan yang berakibat fatal jika diagnosis aritmia yang spesifik ingin ditegakkan lebih dahulu. Diagnosis aritmia dalam keadaan pasien yang tidak stabil dapat ditegakkan kemudian setelah gangguan hemodinamik teratasi.

Gambar 1 jelas suatu takikardia QRS lebar yang regular maka diagnosis banding yang harus dibuat adalah takikardia ventrikel atau takikardia supraventrikel dengan aberansi. Ada 2 kunci pada EKG di atas yang dapat dengan segera membawa pada penegakkan diagnosis pasti dengan cepat, yaitu adanya disosiasi AV dan morfologi RBBB dengan $\mathrm{qR}$ di V1. ${ }^{2,3}$ Disosiasi AV diperlihatkan oleh adanya gelombang $\mathrm{P}$ bebas (anak panah) yang muncul sewaktu-waktu dan tidak berhubungan dengan kompleks QRS. Artinya depolarisasi atrium terjadi tanpa kaitan dengan depolarisasi ventrikel. Laju QRS jelas lebih cepat dari laju P menandakan suatu takikardia ventrikel. Selain itu morfologi qR merupakan tanda lain takikardia ventrikel karena pada takikardia supraventrikel morfologi RBBB di V1 adalah rSR. Menurut Brugada dkk, diagnosis takikardia ventrikel atas dasar adanya disosiasi AV memiliki sensitivitas $82 \%$ dan spesifisitas $98 \%$, bila juga didapatkan morfologi takikardia ventrikel di V1 seperti pada pasien ini maka sensitifitasnya menjadi $98.7 \%$ dan spesifisitas $96.5 \% .^{3}$

\section{Daftar Pustaka}

1. Tachycardia and its ACLS algorithm. ACLS-Algorithm.com. Diunduh April 2013. 
2. Blomström-Lundqvist C, Scheinman MM, Aliot EM, Alpert JS, Calkins H, Camm AJ, Campbell WB, Haines DE, Kuck KH, Lerman BB, Miller DD, Shaeffer CW, Stevenson WG, Tomaselli GF, Antman EM, Smith SC Jr, Alpert JS, Faxon DP, Fuster V, Gibbons RJ, Gregoratos G, Hiratzka LF, Hunt SA, Jacobs AK, Russell RO Jr, Priori SG, Blanc JJ, Budaj A, Burgos EF, Cowie M, Deckers JW, Garcia MA, Klein WW, Lekakis J, Lindahl B, Mazzotta G, Morais JC, Oto A, Smiseth O, and Trappe HJ. ACC/AHA/ESC guidelines for the management of patients with supraventricular arrhythmias--executive summary. a report of the American college of cardiology/American heart association task force on practice guidelines and the European society of cardiology committee for practice guidelines (writing committee to develop guidelines for the management of patients with supraventricular arrhythmias) developed in collaboration with NASPE-Heart Rhythm Society. J Am Coll Cardiol 2003 Oct 15; 42(8) 1493-531.

3. Brugada P, Brugada J, Mont L, Smeets J, and Andries EW. A new approach to the differential diagnosis of a regular tachycardia with a wide QRS complex. Circulation 1991 May; 83(5) 1649-59. 